УДК 504.55.054: 622 (470.6)

\title{
РЕЗЕРВ ПОВЫШЕНИЯ ЭФФЕКТИВНОСТИ РАЗРАБОТКИ МАЛОМОЩНЫХ РУДНЫХ МЕСТОРОЖДЕНИЙ
}

Голик Владимир Иванович ${ }^{1,2}$, v.i.golik@mail.ru

\section{Дмитрак Юрий Витальевич2,} dmitrak@yandex.ru

\author{
Габараев Олег Знаурович², \\ gabaraev59@mail.ru
}

\author{
Стадник Денис Анатольевич2, \\ Sined777@yandex.ru \\ 1 Южно-Российский государственный политехнический университет, \\ Россия, 346428, г. Новочеркасск, ул. Просвещения, 13. \\ 2 Северо-Кавказский государственный технологический университет, \\ Россия, 362021, г. Владикавказ, ул. Космонавта Николаева, 44.
}

Актуальность исследования. Статья посвящена проблеме совершенствования технологии разработки маломощных рудных тел как резерва увеличения производства металлов. Ее актуальность обусловлена ростом дефицита редких и ценных металлов, большинство из которых локализовано в месторождениях рассматриваемого типа.

Цель эксперимента - установить взаимосвязь между геомеханическими условиями разработки рудных месторождений и параметрами очистных работ.

Методика. Основу исследования составляет долговременный промышленный эксперимент на месторождении Ишимское, осуществляемый с использованием геофизических методов мониторинга.

Результаты. Дана оценка перспектив разработки маломощных месторождений с относительно ограниченными запасами. Приведен результат анализа методов управления напряжениями пород в зависимости от их свойств, и описан механизм перехода пород из ненарушенного состояния в нарушенное. Сфрормулирована математическая модель френомена самозаклинивания структурных блоков пород, и дана справка о теории разрушения пород как следствия внутреннего деформирования элементарных минеральных частиц в анизотропной среде. Дано условие сохранности массива от разрушения. Описаны преимущества исследования напряженности пород по величинам упругой и остаточной деформаций. Произведена типизация способов управления массивами по критерию сохранности земной поверхности от разрушения. Приведены результаты использования методов мониторинга в ходе полномаситабной разработки месторождения. Определен экономический эфффект погашения пустот на основе регулирования напряжений.

Выводы. Скальные месторождения металлических руд обладают свойствами, использование которых при подземной разработке позволяет улучшить технико-экономические показатели за счет рационального управления естественными и наведенными напряжениями в ходе мониторинга горных работ с применением методов рудничной геофизики.

Ключевые слова:

Технология разработки, мощность, рудное тело, эксперимент, геомеханика, условия, параметры, геофизический мониторинг.

\section{Введение}

Часть месторождений металлосодержащих руд условно отнесена к группе сложноструктурных. Они отличаются мозаично-глыбовым строением с системами разломов и трещин, что придает рудовмещающим массивам свойства дискретной среды [1-3].

В России запасы таких месторождений преимущественно отработаны на глубину до 1 км. Во всех случаях руды вынимают выборочно, извлекая в благоприятных условиях участки с высоким содержанием металлов.

C середины прошлого века возможности отработки мощных месторождений существенно улучшились за счет заполнения технологических пустот (рис. 1).

Маломощные месторождения с ограниченными запасами отрабатывать по новой технологии в подавляющем большинстве случаев оказывается экономически нецелесообразно. По той же причине ограничены возможности сплошной выемки геометризированных запасов с использованием мощной добычной техники.

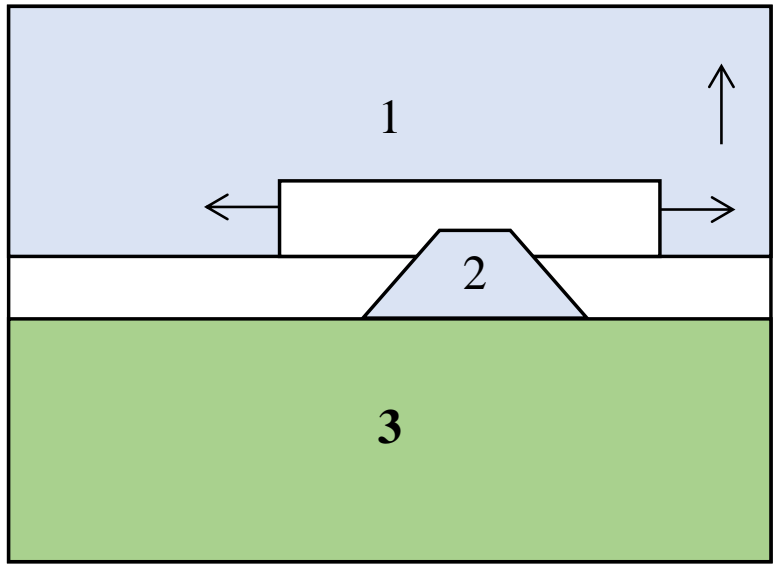

Pис. 1. Система разработки с закладкой: 1 - руда; 2 горная масса; 3 - искусственный массив

Fig. 1. Stowing development system: 1 - ore; 2 - rock mass; 3 - artificial massif 
Актуальность совершенствования технологии разработки маломощных месторождений повышается тем, что в них локализованы редкоземельные, благородные и цветные металлы, потребность в которых неуклонно увеличивается.

Условия устойчивости выработок описаны в работах В. Риттера, А.А. Борисова, С.В. Ветрова, М.М. Протодьяконова, В.Д. Слесарева, П.М. Цимбаревича и др.

Скальные массивы состоят из породных блоков, сохраняющих устойчивость при подработке и обнажении при условии естественного самозаклинивания прижатых друг к другу пород блоков.

Поля напряжений и деформаций в массивах пород формируются в результате взаимодействия соответствующих полей под влиянием техногенных и природных факторов. Зоны нагрузки и разгрузки, способствующие концентрации напряжений, формируют механические системы со слабыми звеньями.

Погашение пустот без заполнения закладочным материалом является исторически самым ранним способом добычи руд при разработке рудных тел небольшой величины в крепких и средней крепости породах.

Целью работ рассматриваемого направления является повышение эффективности выемки руд с использованием не в полной мере реализуемых резервов, одним из которых является управление напряжениями при техногенном вмешательстве в недра [4-7].

В процессе разработки месторождения пользуются инструкции по управлению горным давлением, которые обосновывают ту или иную систему разработки с учетом влияния гидрогеологических, геомеханических и других факторов. Каждое месторождение является уникальным, поэтому инструкции должны быть адаптированы к местным условиям конкретными исследованиями.

Создание в лаборатории физических моделей с учетом всех геолого-структурных факторов является крайне трудозатратным мероприятием, результаты которого сложны в фиксации и обработке. Более доступным является моделирование методом конечных и конечно-дискретных элементов, однако и оно требует специальных возможностей. Для решения частных вопросов горного дела пользуются простыми моделями, условно принимая структурные факторы постоянными.

Такие модели позволяют решать частные горнотехнические вопросы, не затрагивая всего многозвенного кластера геомеханического мониторинга процессов сдвижения горных пород.

\section{Методика исследования}

Цель достигается использованием комплексного метода исследования, включающего критический анализ существующих концепций, моделирование и эксперимент в промышленном масштабе.

Методической основой исследования является теория самозаклинивания структурных блоков пород, развивающая концепцию свода естественного равновесия М.М. Протодьяконова.
Поскольку корректно имитировать нарушенность массива сложно и дорого, применяется модель, в которой строение породных массивов условно принимается одинаковым для сравниваемых вариантов без учета структурных нарушений.

Нагрузка на горные выработки имитируется прессом. Напряжения в элементах модели измеряются датчиками. Такой подход обеспечивает корректность исследования.

Для оценки напряженности пород применен способ Голика-Денисова по соотношению упругой и остаточной деформаций.

\section{Результать}

Образование технологических пустот без закладки способствует росту напряжений и деформаций, что коррелирует с увеличением разубоживания в 1,5-2,0 раза. Методы управления напряжениями пород при отработке маломощных месторождений зависят от свойств вмещающих пород:

- в неустойчивых породах используют крепь;

- при добыче устойчивых руд в недостаточно устойчивых массивах используют магазинированную руду, которая временно стабилизирует напряжения (рис. 2);

- при любых условиях успешно применяют технологии с закладкой твердеющими смесями

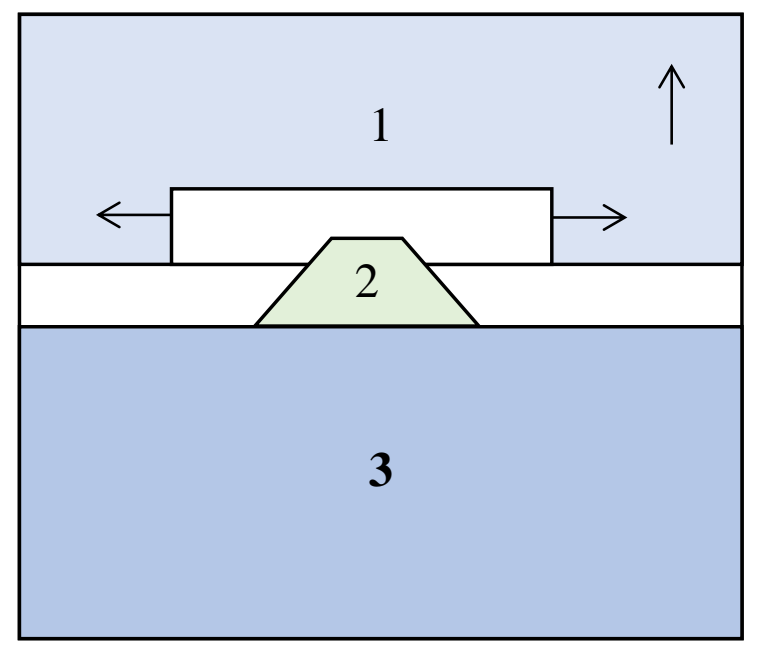

Pис. 2. Система разработки с магазинированием: 1 руда; 2 - горная масса; 3 - магазинированная горная масса

Fig. 2. Development system with stoping: 1 -ore; 2 - rock mass; 3 - storey rock mass

Оптимальна такая модель управления напряжениями, при которой сохранность массива обеспечивается разделением его на участки, где зона развития напряжений пород не достигает поверхности (рис. 3).

Геодинамикой массива управляют, создавая систему, в которой напряжения не достигают критической величины, а зона разрушения пород не достигает земной поверхности [8-10].

Характер перехода пород из ненарушенного состояния в нарушенное определяется соотношением геометрических параметров выработок, в том числе: 
- $\quad$ высот распространения критических напряжений;

- размеров образуемых в массиве выработок; объемов создаваемой в пустотах крепи.

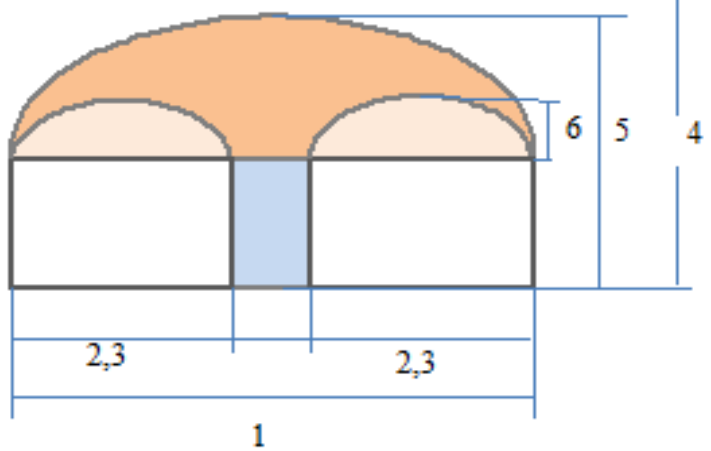

Рис. 3. Схема разделения массива на геомеханически сбалансированные участки: 1 - пролет свода естественного равновесия до разделения; 2 фактический пролет выработки; 3 - пролет с сохранением плоской кровли; 4 - глубина работ; 5 - высота свода естественного равновесия до разделения; 6-высота свода после разделения

Fig. 3. Scheme of division of the array into geomechanically balanced sections: 1 - span of the arch of natural equilibrium before separation; 2 - actual span; 3 span with preservation of a flat roof; 4 - depth of work; 5 - height of the arch of natural equilibrium before separation; 6 - arch height after separation

Параметры предельного свода самозаклинивания структурных блоков пород, предшествующие критическим напряжениям по С.В. Ветрову:

$$
\alpha=d_{1}\left(\frac{10 R_{\text {сж }}^{\prime}}{K H V_{c}}-1\right) \Rightarrow[\sigma]_{\text {крит }}<[\sigma]_{\text {р.п }}^{\text {ост }},
$$

где $\alpha$ - полупролет предельного свода самозаклинивания, м; $d_{1}-$ вертикальный размер структурного блока, $\mathrm{M} ; R_{\text {сж }}^{1}$ - временное сопротивление горных пород структурного блока сжатию (в направлении веса пород в натуре), МПа; $V_{c}$ - объемная масса пород, т/м ${ }^{3} ; H-$ глубина расположения пят свода, м; $K$ - коэффициент запаса; $[\sigma]_{\text {крит }}-$ критические напряжения, МПа; $[\sigma]_{\text {р.п }}^{\text {ост }}$ остаточные напряжения руд и пород, МПа.

При прогнозировании влияния пустот на земную поверхность исходят из того, что без учета величины и знака напряжений создаются условия для разрушения массива $[11,12]$.

Уровень напряжений корректируется изменением характера и скорости высвобождения энергии напряженных пород при опережающей разгрузке напряжений в массиве. При экстремальной нагрузке, согласно кинетической теории прочности, на первой стадии разрушения происходит возбуждение межатомных и межмолекулярных связей и их разрыв под воздействием высвобожденной энергии, а на второй стадии образуются трещины деформации.
Скальные массивы работают в особых условиях. Их несущие элементы работают в режиме непостоянных по величине и знаку деформаций.

При разрушении в запредельной стадии прочность пород уменьшается. На контуре выработки возникает зона нарушенных пород с минимальной прочностью. За ней следует зона ослабленных пород с возрастанием прочности по мере удаления от выработки, переходящая в зону нетронутых пород.

Сохранность массива обеспечивается при минимизации объемов первых двух зон и увеличении доли третьей зоны:

$$
\sigma_{\text {сж.М }}(t)=k_{\mathrm{T}}^{\prime}\left[\sigma_{\text {сж.Д }}+\left(\sigma_{\text {сж.М }}-\sigma_{\text {сж.Д }}\right)\right] e^{-a t},
$$

где $\sigma_{\text {сж.м }}-$ предел мгновенной прочности при одноосном сжатии, МПа; $\sigma_{\text {сж.д }}-$ предел длительной прочности при одноосном сжатии, МПа; $k_{\text {т }}$ коэффициент тектонической нарушенности; $a$ - параметр аппроксимации; $t$ - время.

При подработке массива по нижнему контакту рудного тела высота разгружаемой от напряжений части массива увеличивается, относительная доля зоны запредельных деформаций сокращается, а релаксационные эффекты характеризуются меньшими деформациями.

Напряженность пород измеряется способом Голика-Денисова по соотношению упругой $\left(\varepsilon_{\mathrm{y}}\right)$ и остаточной $\left(\varepsilon_{0}\right)$ деформаций.

Образцы нагружают ступенями с последующей полной разгрузкой образца на каждой ступени до появления остаточной деформации, и по отношению упругой деформации к остаточной судят о напряженности породы (рис. 4).

$$
K_{\text {уд }}=\left(\varepsilon_{\mathrm{м}}-\varepsilon_{\mathrm{o}}\right): \varepsilon_{0} .
$$

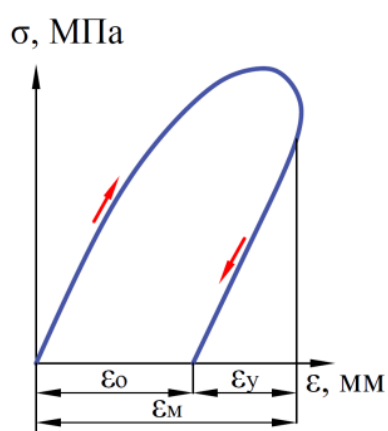

$a / a$

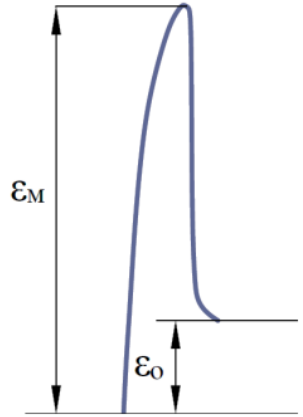

$\sigma / b$
Рис. 4. Параметры деформирования керна: а) график зависимости деформачий от напряжений; б) осииллограмма деформируемости керна при иикличном нагружении

Fig. 4. Parameters of core deformation: a) graph of the strain versus stress; b) oscillogram of core deformability under cyclic loading

Преимущество способа заключается в использовании кернов практически любой длины, в то время как по методике ВНИМИ длина керна больше его диаметра в 2 раза. Коэффициент удароопасности более $70 \%$ свидетельствует о возможности геодинамических явлений [13-15]. 
Регулирование величины напряжений и несущей способности пород путем разгрузки проходкой выработок в массиве позволяет переводить динамические явления в массиве в статические.

Состояние массивов определяется объемом пустот, объемом выданных на поверхность геоматериалов и прочностью породной толщи, отделяющей зону повышенных деформаций от земной поверхности.

Критерием эффективности технологии месторождений является сохранность земной поверхности. По этому критерию способы управления массивом типизированы в рамках таблицы.

Таблица. Типизация способов управления массивами

Table. Array management methods type

\begin{tabular}{|c|c|c|}
\hline $\begin{array}{c}\text { Состояние массива } \\
\text { Array state } \\
\end{array}$ & $\begin{array}{c}\text { Способы управления } \\
\text { Control methods }\end{array}$ & $\begin{array}{c}\text { Условия применения } \\
\text { Conditions of use }\end{array}$ \\
\hline $\begin{array}{l}\text { Естественное обрушение } \\
\text { Natural collapse }\end{array}$ & $\begin{array}{l}\text { с открытыми пустотами } \\
\text { with open voids } \\
\text { с изоляцией пустот } \\
\text { with isolation of voids } \\
\text { с обрушением пород } \\
\text { with caving }\end{array}$ & $\begin{array}{l}\text { руды малой и средней ценности } \\
\text { ores of small and mеdium value } \\
\text { возможность разрушения земной поверхности } \\
\text { possibility of destruction of the earth's surface }\end{array}$ \\
\hline $\begin{array}{l}\text { Принудительное обрушение } \\
\text { Forced collapse }\end{array}$ & $\begin{array}{l}\text { без разгрузки напряжений: } \\
\text { without stress relief: } \\
\text { с твердеющей закладкой } \\
\text { with hardening bookmark; } \\
\text { комбинированные/combined; } \\
\text { с разгрузкой напряжений: } \\
\text { with stress relief: } \\
\text { надработка/overwork; } \\
\text { подработка/part-time; } \\
\text { вертикальными щелями/vertical slots }\end{array}$ & $\begin{array}{l}\text { ценные и весьма ценные руды } \\
\text { valuable and very valuable ores } \\
\text { необходимость сохранения земной поверхности от } \\
\text { разрушения } \\
\text { the need to save the earth's surface from destruction }\end{array}$ \\
\hline
\end{tabular}

Состояние массивов оценивается как функция эффективности охранных мероприятий. Управляемое состояние массивов обеспечивается индивидуальным или совокупным использованием методов разгрузки от повышенных напряжений [16, 17].

Корректность концепции подтверждается практикой разработки Ишимского месторождения (Северный Казахстан) с погашением технологических пустот способом изоляции без закладки.

Месторождение сложено рудными телами шириной от 2 до 15 м, мощностью до 10 м в трещиноватых породах. Угол падения залежей - до 15-25, глубина залегания - до 600 м. Коэффициент крепости руд и пород по М.М. Протодьяконову - 8-14.

Моделированием с масштабом 1:200 исследовали влияние порядка выемки на состояние массива (рис. 5).

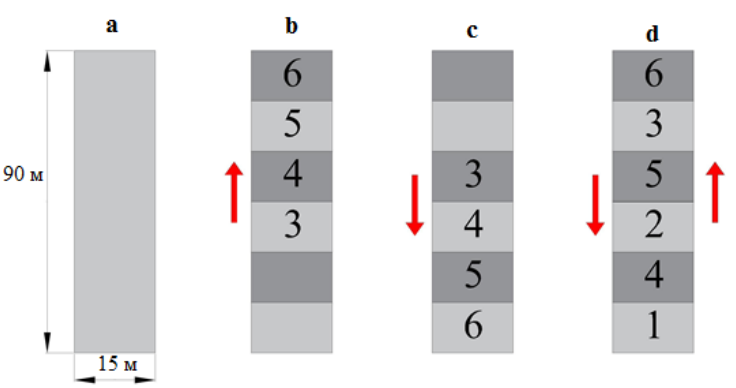

Рис. 5. Моделирование схем отработки: а) размеры модели; b) сплошная наступаюшая выемка; c) сплошная отступающая выемка; d) двухстадийная выемка

Fig. 5. Modeling of mining schemes: a) model dimensions; b) continuous advancing notch; c) continuous retreating recess; d) two-stage recess

Породы и руды в модели представлены песчаноцементной смесью с соотношением 15:1 при водоце- ментном отношении 1,7 и расходе: песок - 170 кг, цемент М 400 - 12 кг, вода - 20 л на порцию, имитирующую $1 \mathrm{~m}^{3}$ горной массы.

Величину горного давления оценивали с помощью деформометров в основании модели, а параметры сдвижения по смещению реперов, установленных над камерами.

Исходные данные для моделирования: глубина работ - 390 м; объемный вес пород - 2,8 т/м ${ }^{3}$; прочность пород на сжатие - 96 МПа; угол падения залежи - 20\%; высота выработки - 3 м.

Ненарушенность массива выработками в модели «а» способствует равномерному распределению давления. В модели «б» давление вследствие проходки нарезных выработок увеличивается на 20-30 \% по сравнению моделью «а». В модели «в» напряжения увеличивается до максимальных размеров. Уменьшение размеров целиков до 2 м способствует развитию опасных напряжений. Звукометрическим методом установлено, что с увеличением длины нарезного штрека с 3 до 10 м импульсы увеличиваются до 5 в минуту.

Устойчивость земной поверхности над месторождением после отработки характеризуется возникновением провалов или сдвижений:

$$
\begin{gathered}
H>H_{p}=55 \ell_{\text {экв }} f^{-1,3}=K \ell_{\text {экв }} ; \\
\ell_{\text {экв }}=\frac{L \cdot \ell^{\prime}}{\sqrt{L^{2}+\left(\ell^{\prime}\right)^{2}}},
\end{gathered}
$$

где $H$ - глубина выработок от поверхности, м; $H_{p}$ расчетная глубина безопасных для поверхности деформаций, м; $\ell_{\text {экв }}$ - эквивалентный пролет выработки, м; - коэффициент крепости пород по Протодьяконову; $L$ - размер выработки по простиранию; $\ell^{\prime}-$ горизонтальная проекция выработки вкрест простирания; $K-$ коэффициент запаса надежности. 
В ходе промышленного эксперимента месторождение с объемом пустот 2 млн м ${ }^{3}$ было погашено без обрушения с воронками и провалами.

Стоимость погашения $1 \mathrm{~m}^{3}$ пустот без закладки в ценах 1990 г. составила 0,18 p./.3. При погашении обрушением пород даже без полного учета влияния на окружающую среду стоимость погашения составила бы $0,92 \mathrm{p} / \mathrm{m}^{3}$, а при закладке пустот твердеющей смесью- $-6-15 \mathrm{p} / \mathrm{m}^{3}$.

Эффективность разработки месторождений зависит от рационального использования свойств рудовмещающих массивов с приоритетом условия сохранности земной поверхности от разрушения. От успеха управления напряжениями зависят и другие показатели эффективности разработки, например выход машинных классов горной массы [18-20].

\section{СПИСОК ЛИТЕРАТУРЫ}

1. Gattinoni P., Pizzarotti E.M., Scesi L. Engineering geology for underground works. - Moscow: Springer, 2014. -312 p.

2. Wang G., Li R., Carranza E.J.M., Yang F. 3D geological modeling for prediction of subsurface Mo targets in the Luanchuan district, China // Ore Geology Reviews. - 2015. - V. 71. - P. 592-610.

3. Zaalishvili V.B., Melkov D.A. Reconstructing the kolka surge on September 20, 2002 from the instrumental seismic data // Izvestiya Physics of the Solid Earth. - 2014. - V. 50. - № 5. - P. 707-718.

4. Величко Д.В., Тюрин Д.В. Геомеханическое обоснование безопасной и эффективной отработки урановых месторождений Приаргунского производственного горно-химического объединения // Горный журнал. - 2018. - № 7. - С. 98-105.

5. Каплунов Д.Р., Рыльникова М.В., Радченко Д.Н. Реализация концепции устойчивого развития горных территорий - базис расширения минерально-сырьевого комплекса России // Устойчивое развитие горных территорий. - 2015. - № 3. - С. 46-50.

6. Новый подход для оценки эффективности работы горнообогатительных комбинатов / И.Т. Мельников, С.Е. Гавришев, А.Г. Михайлов, И.А. Пыталев, Н.С. Шевцов, К.П. Васильев // Горная промышленность. - 2012. - № 5 (105). - С. 60-66.

7. Metal deposits combined development experience / V. Golik, V. Komashchenko, V. Morkun, O. Burdzieva // Metallurgical and Mining Industry. - 2015. - V. 7. - № 6. - P. 591-594.

8. Принципы и экономическая эффективность комбинирования технологий добычи руд / В.И. Голик, Ю.И. Разоренов, С.Г. Страданченко, 3.М. Хашева // Известия Томского политехнического университета. Инжиниринг георесурсов. 2015. - T. 326. - № 7. - C. 6-14.

9. Golik V.I., Razorenov Yu.I., Efremenkov A.B. Recycling of metal ore mill tailings // Applied Mechanics and Materials. - 2014. V. 682 - P. $363-368$.

10. Совершенствование технологии разработки жильных золоторудных месторождений с использованием средств селективной механизированной выемки / А.Ю. Чебан, Г.В. Секисов, А.Г. Секисов, Н.П. Хрунина // Горный журнал. - 2018. № 10. - C. 101-106.

11. Лискова М.Ю., Наумов И.С. Моделирование аварийных ситуаций в шахтах и рудниках // Научные исследования и инновации. -2013 . - Т. 7. - № 1-4. - С. 78-81.

\section{Заключение}

Из полученных результатов исследования следует, что скальные месторождения металлических руд обладают свойствами, использование которых позволяет эксплуатировать их с солидным экологоэкономическим эффектом за счет рационального управления величиной напряжений.

Максимальные напряжения развиваются при стадийной отработке рудных тел, а регулирование напряжений обеспечивается сплошной выемкой залежей и разделением массива на геомеханически сбалансированные участки.

Безопасность отработки обеспечивается мониторингом горных работ с применением методов рудничной геофизики.

12. Strategic mining options optimization: open pit mining, underground mining or both / E. Ben-Awuah, O. Richter, T. Elkington, Y. Pourrahimian // International Journal of Mining Science and Technology. - 2016. - V. 26. - Iss. 6. - P. 1065-1071.

13. Numerical determination of strength and deformability of fractured rock mass by FEM modeling / Y.J. Ping, C.W. Zhong, Y.D. Sen, Y.J. Qiang // Computers and Geotechnics. - 2015. - V. 64. P. 20-31.

14. Borujeni M.P., Gitinavard H. Evaluating the sustainable mining contractor selection problems: An imprecise last aggregation preference selection index method // Journal of Sustainable Mining. 2017. - V. 16. - № 4. - P. 207-218.

15. Комащенко В.И. Разработка взрывной технологии, снижающей вредное воздействие на окружающую среду // Известия Тульского государственного университета. Науки о Земле. 2016. - № 1. - C. 34-43.

16. Ensuring safe operation and assessing the condition underground structures by the method of acoustic resonance flaw detection / B. Meskhi, M. Pleshko, Y. Buligin, L. Alexeenko, M. Molev // IOP Conference Series: Earth and Environmental Science. 2017. - P. 212-217.

17. Масленников С.А. К вопросу о проектировании крепи вертикальных стволов в сложных горно-геологических условиях // Горный информационно-аналитический бюллетень (научнотехнический журнал). - 2016. - № 6. - С. 50-55.

18. Повышение полноты использования недр путем глубокой утилизации отходов обогащения угля / В.И. Голик, В.И. Комащенко, С.Г. Страданченко, С.А. Масленников // Горный журнал. - 2012. - № 9. - С. 91-95.

19. Выбор средств защиты высоковольтного двигателя экскаватора на руднике открытых работ горно-металлургического комбината / Р.В. Клюев, И.И. Босиков, О.А. Гаврина, В.А. Атрушкевич // Безопасность труда в промышленности. 2020. - № 7. - C. 46-53.

20. Оценка устойчивости и обводненности породного массива геофизическими методами / В.В. Романов, К.С. Мальский, А.И. Посеренин, А.Д. Каринский // Горный журнал. - 2018. № 11. - C. 65-71.

Поступила 17.06.2020 г.

\section{Информация об авторах}

Голик В.И., доктор технических наук, профессор, профессор кафедры горного дела, Южно-Российский государственный политехнический университет; профессор кафедры горного дела Северо-Кавказского государственного технологического университета.

Дмитрак Ю.В., доктор технических наук, профессор, ректор Северо-Кавказского государственного технологического университета.

Габараев О.3., доктор технических наук, профессор, заведующий кафедрой горного дела Северо-Кавказского государственного технологического университета.

Стадник Д.А., доктор технических наук, профессор кафедры горного дела Северо-Кавказского государственного технологического университета. 
UDC 504.55.054: $622(470.6)$

\title{
RESERVE FOR INCREASING EFFICIENCY OF DEVELOPMENT OF LOW-POWERED ORE DEPOSITS
}

\author{
Vladimir I. Golik ${ }^{1,2}$ \\ v.i.golik@mail.ru \\ Yury V. Dmitrak2, \\ dmitrak@yandex.ru
}

Oleg Z. Gabaraev², gabaraev59@mail.ru

\author{
Denis A. Stadnik2, \\ Sined777@yandex.ru \\ 1 South-Russian State Polytechnic University, \\ 13, Prosvesheniya street, Novocherkassk, 346428, Russia \\ 2 North Caucasian State Technological University, \\ 44, Nikolaev street, Vladikavkaz, 362021, Russia.
}

The relevance of the research. The article is devoted to the problem of improving the technology of developing thin ore bodies as a reserve for increasing the production of metals. Its relevance is due to the growing deficit of rare and valuable metals, most of which are localized in deposits of the type under consideration.

The aim of the experiment is to establish the relationship between the geomechanical conditions of the development of ore deposits and the parameters of the treatment works.

Methodology. The research is based on a long-term industrial experiment at the Ishim field, carried out using geophysical monitoring methods.

Results. The prospects of developing low-power deposits with relatively limited reserves are estimated. The article presents the result of the analysis of methods for controlling rock stresses depending on their properties and describes the mechanism of rock transition from an unbroken state to a broken state. A mathematical model for the phenomenon of self-jamming of structural blocks is formulated and a reference is given to the theory of rock destruction as a consequence of the internal deformation of elementary mineral particles in an anisotropic medium. The article explains the condition of the array preservation from destruction. The advantages of studying the stress of rocks by the values of elastic and residual deformations are described. The typification of methods for managing arrays by the criterion of the preservation of the earth's surface from destruction was made. The results of the use of monitoring methods during the full-scale development of the field are presented. The economic effect of the repayment of voids based on the regulation of stresses is determined.

Conclusions. Rock deposits of metal ores have properties the use of which in underground mining can improve technical and economic indicators due to the rational management of natural and induced stresses during monitoring of mining operations using the methods of mining geophysics.

Key words:

Development technology, power, ore body, experiment, geomechanics, conditions, parameters, geophysical monitoring.

\section{REFERENCES}

1. Gattinoni P., Pizzarotti E.M., Scesi L. Engineering geology for underground works. Moscow, Springer, 2014. $312 \mathrm{p}$.

2. Wang G., Li R., Carranza E.J.M., Yang F. 3D geological modeling for prediction of subsurface Mo targets in the Luanchuan district, China. Ore Geology Reviews, 2015, vol. 71, pp. 592-610.

3. Zaalishvili V.B., Melkov D.A. Reconstructing the Kolka surge on September 20, 2002 from the instrumental seismic data. Izvestiya Physics of the Solid Earth, 2014, vol. 50, no. 5, pp. 707-718. In Rus.

4. Velichko D.V., Tyurin D.V. Geomechanical substantiation of safe and effective mining of uranium deposits of the Priargunsky industrial mining and chemical association. Mining Journal, 2018, no. 7 , pp. 98-105. In Rus.

5. Kaplunov D.R., Rylnikova M.V., Radchenko D.N. The implementation of the concept of sustainable development of mountainous territories is the basis for the expansion of the mineral resource complex of Russia. Sustainable development of mountainous areas, 2015, no. 3, pp. 46-50. In Rus.

6. Melnikov I.T., Gavrishev S.E., Mikhailov A.G., Pytalev I.A Shevtsov N.S., Vasiliev K.P. A new approach for evaluating the efficiency of mining and processing plants. Mining, 2012 no. 5 (105), pp. 60-66. In Rus.
7. Golik V., Komashchenko V., Morkun V., Burdzieva O. Metal deposits combined development experience. Metallurgical and Mining Industry, 2015, vol. 7, no. 6, pp. 591-594.

8. Golik V.I., Razorenov Yu.I., Stradanchenko S.G., Khasheva Z.M. Principles and cost-effectiveness of combining ore mining technologies. Buuletin of the Tomsk Polytechnic University. Geo Assets Engineering, 2015, vol. 326, no. 7, pp. 6-14. In Rus.

9. Golik V.I., Razorenov Yu.I., Efremenkov A.B. Recycling of metal ore mill tailings. Applied Mechanics and Materials, 2014, vol. 682, pp. 363-368.

10. Cheban A. Yu., Sekisov G.V., Sekisov A.G., Khrunina N.P. Improving the development of vein gold ore deposits using selective mechanized excavation. Gorny Zhurnal, 2018, no. 10, pp. 101-106. In Rus.

11. Liskova M.Yu., Naumov I.S. Modeling emergency situations in mines and mines. Scientific research and innovation, 2013, vol. 7, no. 1-4, pp. 78-81. In Rus.

12. Ben-Awuah E., Richter O., Elkington T., Pourrahimian Y. Strategic mining options optimization: Open pit mining, underground mining or both. International Journal of Mining Science and Technology, 2016, vol. 26, Iss. 6, pp. 1065-1071.

13. Ping Y.J., Zhong C.W., Sen Y.D., Qiang Y.J. Numerical determination of strength and deformability of fractured rock mass by FEM modeling. Computers and Geotechnics, 2015, vol. 64, pp. 20-31. 
14. Borujeni M.P., Gitinavard H. Evaluating the sustainable mining contractor selection problems: An imprecise last aggregation preference selection index method. Journal of Sustainable Mining, 2017, vol. 16, no. 4, pp. 207-218.

15. Komashchenko V.I. The development of explosive technology that reduces the harmful effects on the environment. Bulletin of Tula State University. Earth Sciences, 2016, no. 1, pp. 34-43. In Rus.

16. Meskhi B., Pleshko M., Buligin Y., Alexeenko L., Molev M. Ensuring safe operation and assessing the condition underground structures by the method of acoustic resonance flaw detection. IOP Conference Series: Earth and Environmental Science, 2017, pp. 212-217.

17. Maslennikov S.A. To the question of designing the support of vertical shafts in difficult mining and geological conditions. Mining Information and Analytical Bulletin (scientific and technical journal), 2016, no. 6, pp. 50-55. In Rus.

\section{Information about the authors}

Vladimir I. Golik, Dr. Sc., professor, South-Russian State Polytechnic University; professor, North Caucasian State Technological University.

Yury V. Dmitrak, Dr. Sc., professor, rector, North Caucasian State Technological University.

Oleg Z. Gabaraev, Dr. Sc., professor, head of the Mining Department, North Caucasian State Technological University.

Denis A. Stadnik, Dr. Sc., professor, North Caucasian State Technological University.
18. Golik V.I., Komashchenko V.I., Stradanchenko S.G., Maslennikov S.A. Improving the completeness of the use of mineral resources through the deep utilization of coal enrichment waste. Mountain Journal, 2012, no. 9, pp. 91-95. In Rus.

19. Klyuev R.V., Bosikov I.I., Gavrina O.A., Atrushkevich V.A. Selection of protective equipment for the high-voltage motor of an excavator at an open pit mine of a mining and metallurgical plant. In Rus.

20. Romanov V.V., Malsky K.S., Posenin A.I., Karinsky A.D. Assessment of stability and watering of the rock mass using geophysical methods. Gorny Zhurnal, 2018, no. 11, pp. 65-71. In Rus.

Received: 17 June 2020 Bezopasnost truda y promyshlennosti, 2020, no. 7, pp. 46-53. 